\title{
Exérese de lipoma em papagaio-verdadeiro (Amazona aestiva)
}

\author{
Lipoma exeresis in blue-fronted parrot (Amazona aestiva)
}

Fabrício Singaretti de Oliveira, Leandro Luís Martins, Aline Delfini \& Domingos de Faria Junior

\begin{abstract}
RESUMO
Lipomas são tumores freqüentes no tecido subcutâneo, de crescimento lento e benigno, podendo ser encontrados em tecidos mais profundos, como os músculos, órgãos abdominais e torácicos, na cavidade oral e no crânio. Este relato descreveu um caso de lipoma em um papagaio-verdadeiro, mantido em cativeiro na região de Fernandópolis, SP. O animal, de aproximadamente 10 anos de idade e 485 gramas, apresentava dificuldade de locomoção devido ao grande aumento de volume, progressivo há alguns meses e localizado na região adcloacal direita. Não foram evidenciadas alterações comportamentais ou na ingestão de alimentos ou água. À palpação, o nódulo apresentava consistência macia e pequenas áreas crostosas cutâneas. Foi conduzido o exame radiográfico e biópsia aspirativa com agulha e o animal foi submetido à cirurgia para exérese do nódulo, sendo realizada indução anestésica intra-muscular com diazepam e cetamina e manutenção por isoflurano. No período pósoperatório foram realizadas aplicações de antibiótico, antiinflamatório e analgésico. O nódulo extraído pesou 62 gramas, correspondendo a 12,8\% do peso corpóreo, e foi processado histologicamente, revelando a presença de adipócitos bem definidos, com citoplasma desenvolvido e núcleos periféricos.
\end{abstract}

Descritores: lipoma, papagaio-verdadeiro, Amazona aestiva, cirurgia.

\begin{abstract}
Lipomas are usual tumors on subcutaneous tissue and present slow and benign development, occurring even in deep tissues, as muscles, abdominal and thoracic organs, the oral cavity and the skull. This report described a case of lipoma in a blue-fronted parrot, kept in captivity in Fernandópolis, SP, area. The around 10 year-old animal weight 485 grams and presented difficulty for locomotion due the enormous volume of the mass, which was progressively during the last months and was situated on the right adcloacal region. There were no behavior, feeding or drinking changes. By palpation, the nodule presented soft aspect and several skin lesions. Radiographic examination and aspirative needle biopsy were performed and the animal went for surgery for nodule exeresis, by using intramuscular anesthesic induction with diazepam and ketamine and manutention by isofluorane. Antibiotics, anti-inflammatory and analgesics were administered on postoperative time. The nodule weighted 62 grams, corresponding to $12.8 \%$ of the body weight, and histologically demonstrated the presence of well defined adipocites, with large cytoplasm and peripheral nuclei.
\end{abstract}

Key words: lipoma, blue-fronted parrot, Amazona aestiva, surgery. 


\section{INTRODUÇÃO}

Lipomas são tumores freqüentemente encontrados nos tecido subcutâneo, de crescimento lento e benigno [1]. Entretanto, em algumas aves pode ocorrer o aparecimento de novas massas tumorais após remoção cirúrgica dos focos primários [7]. Esses tumores também podem ser encontrados em tecidos mais profundos, como os músculos, órgãos abdominais e torácicos, na cavidade oral e no crânio $[4,10]$.

Os lipomas usualmente apresentam-se como massas globulares, amareladas [7], não-dolorosas, móveis e macias à palpação, e sem alteração no tecido cutâneo envolvente [8].

Lipomas no tecido subcutâneo ocorreram em uma cacatua (Kakatoe roseicapilla) macho de 39 anos e em 38 periquitos-australianos (Melopsittacus undulatus). Os periquitos apresentavam entre um e meio e oito anos de idade e $76 \%$ deles eram machos. A maioria dos tumores localizava-se no esterno, asas e abdome e uma pequena porcentagem acometeu o dorso, pescoço e glândula uropigiana [7].

\section{RELATO DO CASO}

O objetivo desse relato foi descrever um caso de lipoma em um papagaio-verdadeiro, mantido em cativeiro na região de Fernandópolis, SP. O animal, de aproximadamente 10 anos de idade e 485 gramas, foi atendido no Hospital Veterinário da UNICASTELO, Campus Fernandópolis, SP. O mesmo apresentava dificuldade de locomoção pelos poleiros da gaiola utilizada como recinto, devido ao grande aumento de volume, progressivo há alguns meses e localizado na região adcloacal direita (Figura 1). Não foram evidenciadas alterações comportamentais ou na ingestão de alimentos ou água. À palpação, o nódulo apresentava consistência macia e pequenas áreas crostosas cutâneas. Havia queda de pena em aproximadamente 50\% da extensão do nódulo, com evidenciação da pele. Foi conduzido o exame radiográfico, no qual evidenciou-se imagem radiolucente adcloacal, bem circunscrita, sem alterações ósseas locais, compatível com tecido gorduroso. Realizou-se biópsia aspirativa com agulha, verificando-se a presença de grande quantidade de adipócitos no nódulo.

$\mathrm{O}$ animal foi submetido à cirurgia para exérese do nódulo, sendo realizada indução anestésica intramuscular com diazepam ${ }^{1}(1,5 \mathrm{mg} / \mathrm{kg})$ e cetamina ${ }^{2}(15$ $\mathrm{mg} / \mathrm{kg}$ ) e manutenção durante 30 minutos por isoflu-

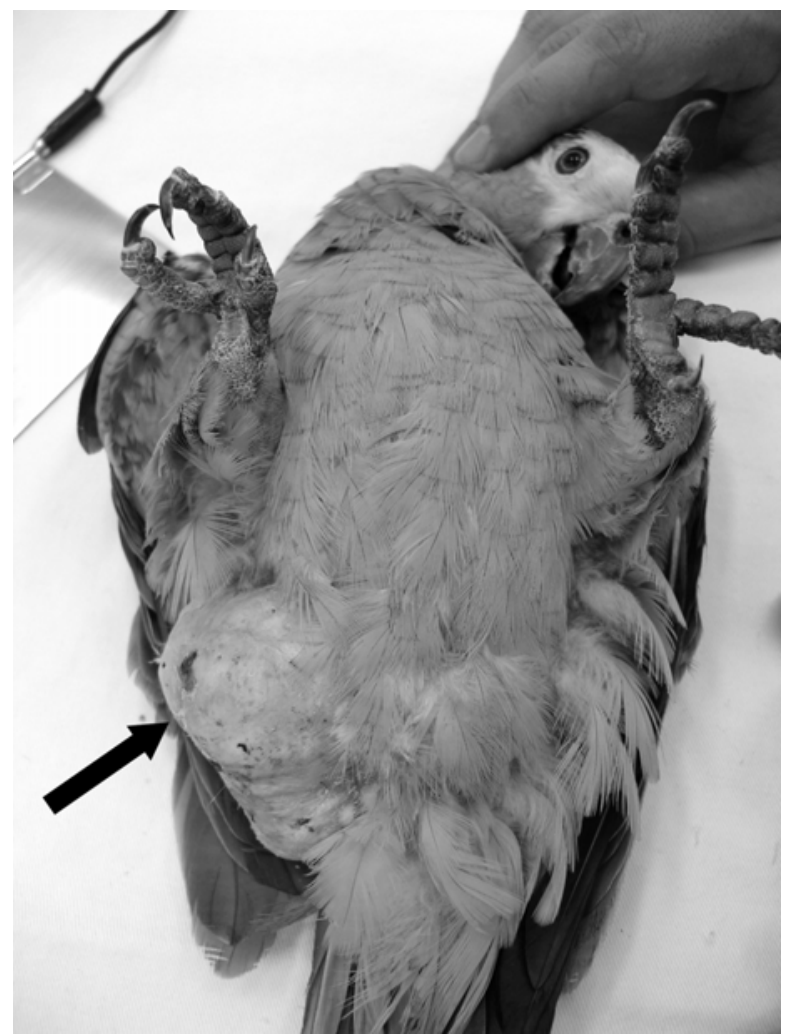

Figura 1. Grande aumento de volume (seta) localizado na região adcloacal direita em papagaio-verdadeiro de 10 anos de idade, com diagnóstico de lipoma.

rano $^{3}$ em máscara. No período pós-operatório foram realizadas aplicações de pentabiótico ${ }^{4}(30.000 \mathrm{UI} / \mathrm{kg}$ de três penicilinas e $12,5 \mathrm{mg} / \mathrm{kg}$ de duas espreptomicinas) em dias alternados durante 6 dias, além de antiinflamatório e analgésico (meloxicam ${ }^{5} 0,4 \mathrm{mg} / \mathrm{kg}$, durante 3 dias seguidos) e o animal foi mantido com colar elizabetano feito com pedaço de radiografia (Figura 2). O nódulo extraído possuía 6,5 centímetros de diâmetro e pesou 62 gramas, correspondendo a $12,8 \%$ do peso corpóreo. $\mathrm{O}$ mesmo foi processado histologicamente, revelando a presença de adipócitos bem definidos, com citoplasma desenvolvido e núcleos periféricos.

\section{DISCUSSÃO}

Os sinais clínicos foram relacionados ao tamanho e localização do tumor e incluíam dificuldade de vôo e locomoção, e automutilação local [7].

$\mathrm{O}$ animal apresentava-se obeso, o que pode têlo tornado mais susceptível à ocorrência desse tumor [6,7], estando esta obesidade associada à dieta inadequada e altamente energética, à base de sementes de girassol, além de pouca atividade física e estresse de cativeiro [3]. 


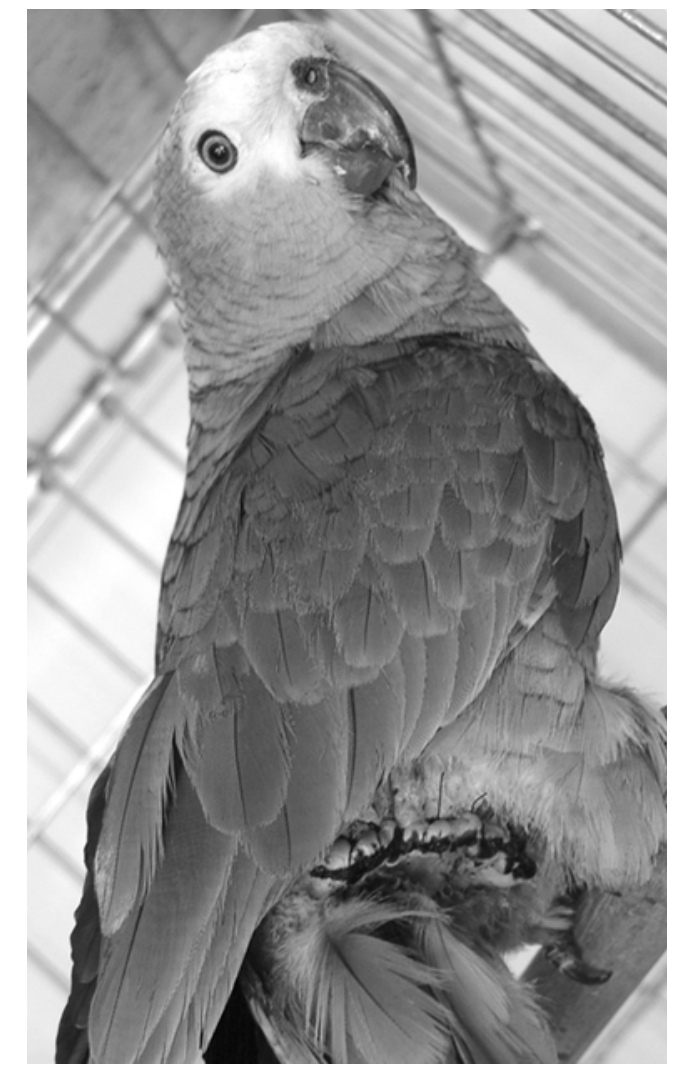

Figura 2. Papagaio-verdadeiro durante o período pós-operatório que evoluiu para a cura do quadro de lipoma.
Os diagnósticos diferenciais incluíram abscesso, liposarcoma, cisto epidermóide e doença metastática [4,10], e foram descartados mediante exame radiográfico e cito/histopatológico.

A excisão cirúrgica do lipoma resultou em cura [8], não havendo a ocorrência de recidiva durante os 10 meses no qual o animal foi acompanhado clinicamente após a cirurgia. Não houve formação de hematoma, lesão em nervos, injúrias musculares, embolia gordurosa ou seroma [8]. A lipossucção do tumor com seringa e agulha não foi adotada pois raramente permite a completa retirada do mesmo [9].

Microscopicamente, o lipoma revelou a presença de adipócitos bem definidos e arranjados em lóbulos, com citoplasma desenvolvido e núcleos periféricos [2,5].

\section{NOTAS INFORMATIVAS}

${ }^{1}$ Dienpax $^{\circledR}$ - Sanofi Winthrop - Rio de Janeiro, RJ, Brasil. ${ }^{2}$ Vetaset $^{\circledR}$ - Fort Dodge Saúde Animal Ltda. - Campinas, SP, Brasil.

${ }^{3}$ Forane ${ }^{\circledR}$ - Abbott Laboratórios Ltda. - São Paulo, SP, Brasil. ${ }^{4}$ Pentabiótico Veterinário ${ }^{\circledR}$ - Fort Dodge Saúde Animal Ltda. - Campinas, SP, Brasil.

${ }^{5}$ Movatec $^{\circledR}$ - Boehringer Ingelheim - São Paulo, SP, Brasil.

\section{REFERÊNCIAS}

1 Anders K. H. \& Ackerman A. B. 1999. Neoplasms of the subcutaneous fat. In: Freedberg I.M., Eisen A.Z., Wolff K., Austen K.F., Goldsmith L.A. \& Katz S.I. (Eds). Fitzpatrick's Dermatology in General Medicine. 5th edn. New York: McGraw-Hill, pp.1292-1300.

2 Austin R. M., Mack G. R., Townsend C. M. \& Lack E. E. 1980. Infiltrating (intramuscular) lipomas and angiolipomas. A clinicopathologic study of six cases. Archives of Surgery. 115: 281-284.

3 Carciofi A. C. 2001. Nutrition. In: Fowler M. E. \& Cubas Z. S. (Eds). Biology, Medicine and Surgery of South American Wild Animals. pp.152-157.

4 Koh H. K. \& Bhawan J. 1992. Tumors of the skin. In: Moschella S.L. \& Hurley H.J. (Eds). Dermatology. 3rd edn. Philadelphia: Saunders, pp.1721-1808.

5 Lerosey Y., Choussy O., Gruyer X., Francois A., Marie J. P. \& Dehesdin D. 1999. Infiltrating lipoma of the head and neck. Internal Journal of Pediatric Otorhinolaryngology. 47: 91-95.

6 Pachaly J. R. 1992. Doenças nutricionais das aves silvestres cativas. In: Medicina de Animais Selvagens. Curitiba. pp.120-121.

7 Petrak M. L. 1982. Neoplasms. In: Petrak M. L. \& Gilmore C. E. (Eds.). Diseases of cage and aviary birds. 2nd edn. Philadelphia: Lea \& Febiger, pp.606-637.

8 Salam G. A. 2002. Lipoma Excision. American Family Physician. 65: 901.

9 Wilhelmi B. J., Blackwell S. J., Mancoll J. S. \& Phillips L. G. 1999. Another indication for liposuction: small facial lipomas. Plastic and Reconstructive Surgery. 103: 1864-1867.

10 Zimmermann M., Kellermann S., Gerlach R. \& Seifert V. 1999. Cerebellopontine angle lipoma. Acta Neurochirurgica. 141: 1347-1351.

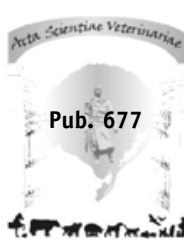

